\title{
Ambivalences: Voices of Indonesian Academic Discourse Gatekeepers
}

\author{
Yazid Basthomi ${ }^{1}$ \\ ${ }^{1}$ English Department, Faculty of Letters, Universitas Negeri Malang (State University of Malang), Indonesia \\ Correspondence: Yazid Basthomi, English Department, Faculty of Letters, Universitas Negeri Malang (State \\ University of Malang), Jl. Semarang 5 Malang, Jawa Timur, 65145, Indonesia. Tel: 62-341-551312. E-mail: \\ ybasthomi@um.ac.id
}

Received: May 8, 2012 Accepted: May 17, 2012 Online Published: July 1, 2012

doi:10.5539/elt.v5n7p17 URL: http://dx.doi.org/10.5539/elt.v5n7p17

\begin{abstract}
This article presents voices of academic discourse gatekeepers in the Indonesian context. It reports on results of an attempt to re-read (re-analyze and re-interpret) the transcripts of interviews with Indonesian journal editors/reviewers in the area of English Language Teaching (ELT). The interviews were made with five editors/reviewers of two Indonesian-based journals. An interesting surfacing issue is the ambivalences or paradoxes experienced by the editors/reviewers. Directions for future research and implications of the ambivalences for more balanced world academic discourse will conclude the essay.
\end{abstract}

Keywords: ambivalence, reviewers, editors, journal, ELT, academic discourse gatekeepers, Indonesia

\section{Introduction}

Concerns about the voices (ideas, thoughts) of both native speakers and non-native speakers of English, be they through writing or speaking, have been proliferating (see e.g., Kang, 2006; Tsui, 2007). Such concerns have been the prime locus of narrative research (see e.g., Blanton, 2009; Hayes, 2010; Nelson, 2011; Schnee, 2009; Xu and Connelly, 2010). Whilst Kang (2006) analyzed and compared some cultural voices of Americans and Koreans in their narrative writings, Tsui (2007) researched into the voices of a professional having a career in the area of teaching English as a foreign language in the academic context of China. In the Indonesian academic context, studies carried out by Mirahayuni (2002) and Adnan (2004) can be deemed to exemplify these kinds of concerns.

In her discussion of the writer's performance in writing research articles (RAs), Mirahayuni (2002) did not attend to the voices of parties other than the research article writers themselves. Adnan (2004), to some extent, makes reference to journal editors in explaining the citation behavior of Indonesian RA writers, which reflect their ideas about citation practice. It seems that Mirahayuni (2002) has relegated to the idea that it is sufficient to know the Indonesian writers' writing performance and voices by inferring them from the texts they produce. This is what has been extensively done by content analysts (Fraenkel and Wallen, 2003). However, we need to keep in mind that the realization of the ideas in writing, specifically research articles (RAs), is very much dependent on the evaluation and editing process of journal reviewers and/or editors, for RAs take their final forms through some chains of editing and redrafting (Swales, 2004). As such, there are parties other than the RA writers themselves who contribute to the shaping of the writers' voices in RAs.

A study more focused on the voices of journal reviewers and/or editors has been carried out by Flowerdew (2001). Taking journal reviewers and/or editors as influential gatekeepers to the realization of published articles, Flowerdew (2001) insightfully reported on the voices of international journal editors regarding the contributions of non-native English writers. Among the important points reported, he mentioned some problematic aspects of non-native English contributors. These include surface errors, parochialism, absence of authorial voice, and nativized varieties of English. He also made a specific mention of Introduction and Discussion as the most problematic sections of research articles (Flowerdew, 2001: 127).

However, voices of gatekeepers of Indonesian academic discourse have hitherto remained under-researched. Safnil (2000), Mirahayuni (2002), and Adnan (2004) who have pioneered works delving into the area of Indonesian academic discourse have not produced sufficient records of the voices. Basthomi (2007), despite his report on the expectations of the Indonesian academic gatekeepers, did not touch on the ambivalences of the gatekeepers regarding their assignment to assume the designated position as reviewers and/or editors.

Germane to the above issue, this paper will report on the results of re-reading of my interviews with Indonesian gatekeepers of academic discourse, the gatekeepers being those reviewing and/or editing academic manuscripts 
written in English to be published in Indonesian-based journals (Basthomi, 2006a). Since this study has to do with academics in a peripheral area, it adds to the voices of those in the periphery as documented by, for instance, Hayes (2010), and Cadman and Brown (2011).

This re-reading is warranted, for, despite the argument of the intentionality of the speakers (Montminy, 2010), including research subjects in their responses to interview questions, any utterance is subject to concomitant exuberances and deficiencies (Ortega quoted in Becker, 1996). What Ortega has purported exponentially echoes in the literature on narrative research (see e.g., Bell, 2011; Schnee, 2009). As has been widely argued particularly in the area of narrative research, the meanings of utterances are not necessarily fixed in a particular time for a particular purpose, but rather, are indeterminate and dynamic, depending on some factors such as time and context of the interpreters (see, e.g., Bell, 2011; Blanton, 2005; Schnee, 2009), for interpreters have stocks of intertextuality in the moment and process of interpreting (Gordon, 2009; Sipe, 2008).

In the area of social sciences in general and applied linguistics (particularly language pedagogy), this indeterminacy is not to be deemed a failure in understanding meanings of narratives, but rather constitutive of an array of potential meanings the instantiation and uses of which function to hone transformation (Johnson \& Golombek, 2011; Schnee, 2009), for what is more important is not the fixity of meanings but insights from the dynamism of the narratives (Nelson, 2011). It is in light of this argument that the present study is carried out.

\section{Method}

This section presents information on how the voices were elicited. Imperative for this purpose is a presentation of the information about the subjects from whom the data, which fall into the category of small stories, were documented; the data were categorized into small stories, for they exist within and as integral parts of interactions in everyday mundane life (Vásquez, 2011).

\subsection{Research Subjects}

In the attempt to select the journal editors and/or reviewers, I set the following guides: 1) the journal reviewers are Indonesian, 2) the journal editors and/or reviewers are appointed to review and/or edit article(s) written in English, and 3 ) the journal reviewers are appointed with the right to recommend if certain articles deserve publication, should undergo revision before publication, or should be refused. These criteria were needed to ensure that the subjects had voices pertinent to issues around the publication of articles written in English within the context of non-English postcolonial Indonesia against the backdrop of international academic discourse which uses English as a pivotal medium of communication.

Referring to the criteria, I learned that some reviewers had been appointed solely as reviewers and some reviewers have also served as editors (implicative of editing and administrative responsibilities for the publication of the given journals). It can be safely assumed that the editors-reviewers are quite knowledgeable of the "A to Z" mechanism of the article selection and publication. The following details particulars about the five subjects from whom I managed to secure consents for interviews.

The first subject (S1) is an editor-reviewer. S1 serves as a chief editor for one of the journals and a reviewer for both journals. S1 had completed bachelor, master's, and doctoral degrees in an Indonesian university. In conjunction with those degrees, S1 also had undertaken an eleven-month graduate diploma in TESL in one of New Zealand universities. Similar to S1, the second subject (S2) was (and is) an editor-reviewer; S2 works as an editor for the two journals selected, and, at times, also works as a reviewer. In addition to working for the two journals selected, S2 also serves as an editor for some other publications. S2 completed a first degree in Indonesia, master's degree in a university in England, and a Ph.D. in an Australian university. Besides, S2 also once attended a specialist certificate program at the Regional Language Centre (RELC), Singapore.

The third subject (S3) is an editor with one of the two journals aforementioned. S3 earned a first degree from an Indonesian university and obtained a master's degree from a British university. The fourth subject (S4) is a reviewer for one of the two journals selected. S4 holds degrees of doktorandus and doctor from one of Indonesian universities. In addition to such degrees, S4 also undertook some short courses in two North American universities which lasted for some 6 months and 10 months respectively. And the fifth subject (S5) is an editor for one of the two journals. S5 completed a bachelor degree in one of Indonesian universities. Furthermore, S5 also earned an M.A. from an Australian university. In brief, the majority of the subjects selected had had some experience of living and ever been exposed to academic atmosphere abroad and mainly in English speaking countries. It needs adding that all the journal editors and/or reviewers selected have majors which fall into the area of applied linguistics or educational linguistics or language education. 


\subsection{Activities Prior to Interviews}

The activities prior to interviews were mainly in the form of making contacts with the selected interviewees. The activities were in the forms of correspondence through mainly (cell) phones. The correspondence included attempts to give information about the topic of the research, focus of the interviews, and the time needed for the interviews. All this was meant to make sure that the research met the ethical consideration regarding research involving human subjects. And all the subjects were willing to participate in the project (consent was secured from each subject).

\subsection{Interviews}

On the basis of Seidman's (1991) experience which was adapted to prepare the interviews, the interviews with each interviewee were conducted on three focuses. The first focused on the "historical" account of the interviewees with regard to the topic to research on. In the case of the present research, the researcher concentrated on the "history" of the interviewees as journal editors and/or reviewers, depending on their position. The second concentration was on what the interviewees do in relation to their current activities as journal reviewers and/or editors. The third focus was on how the interviewees see their "history" and present activities (Seidman, 1991).

Seidman (1991) suggests that the three focuses constitute three interviews with each interviewee. He further suggests that a week is fine as the time interval between the three interviews. However, as was the case with the present research, I made some changes of the suggestion particularly for some adjustment to the time availability of the interviewees. At times, I could manage to have three separate interviews with one individual. But on most occasions, I had to be content with one-off interviews covering the three focuses.

The interviews lasted for approximately 30 minutes for each interviewee. It needs adding, though, that there were other 60 minutes for confirmatory sessions with two interviewees. These additional interviews occurred during the initial interviews with the first two subjects. This, in part, was due to the double capacity of the subjects, i.e., (chief) editor and reviewer simultaneously; so, confirmation on clear ideas of the two positions was deemed crucial. Another part of the reason was that the interviews were still the beginning; they thus required more time for the execution. So, the interviews took some 210 minutes. This figure is derived from the multiplication of 30 minutes with 5 subjects, which is equal to 150 minutes. The other 60 more minutes accrued from 30 additional minutes of initial interviews with two subjects and added to 150 minutes result in 210 minutes or 3.5 hours.

\subsection{Data Analysis}

As noted earlier, this study is a re-reading of the interview transcripts of a larger research project (Basthomi, 2006a). As conventionalized in qualitative research (see e.g., Bell, 2011; Schnee, 2009), inductive analysis was carried out, the detail of which can be read in Basthomi (2006a). As a re-analysis and re-interpretation of the existing data with a particular purpose, the focus of the analysis was on the voices of the subjects pertinent to their appointment as reviewers and/or editors, which was not attended to in the first interpretation of the data when the major research project was completed. This re-analysis resulted in the following.

\section{Findings}

There is one salient issue surfacing in the re-reading of the narratives of the subjects: pessimism. To give an illustration, the pessimism relates to an editor's judgment, based on her observations, of the parochial characteristic of the articles written by Indonesian academics. This pessimism particularly has to do with a question related to the issue of international orientation of the journal she is responsible for. Quote 1 epitomizes this issue.

Quote 1

S2: I would think of the possibility of articles in science ((in Indonesia)) to keep up with international trends. But, I have my doubt of articles ((in the area of education)) which are too local or parochial, referring only to particular school in one town in Indonesia. Without novelty, I'm not sure about the internationalization. But, again, the question of novelty is really a big question ((laughter)). As with chemistry, for instance, I would say it has the potential for international readership.

$\mathrm{S} 2 / \mathrm{I}-04 / 04 / 05$

Echoing S2, another editor (S4) also commented on the mediocre quality of the articles written by Indonesian academics. Due to this situation, she would not dare to imagine international readership of the journal for which she was editor (see Quote 2).

Quote 2

S4: Definitely. For, in the absence of international orientation, many Indonesian writers already find 
difficulties meeting the requirements ((let alone when the higher demands of international orientation are effected)). As I've noted earlier, the writers have difficulties, ranging from the relevance of the topic selection to theoretical underpinnings. So, if we install higher requirements, only very few would be able to pass the screening ((laughter)). Well, I wish I could demand higher, but, that's the fact of what I've done in the reviewing process. Part of the issue might be the absence of clear guidelines for reviewers. To be frank, I'm not quite clear how far I should go to review the manuscripts sent to me, whether I should limit myself to evaluate only the content, or the theory, and the like or if I'm supposed to give only notes why is it like this or that or if I'm supposed to provide step by step ways how to arrive at a better manuscript. In the same vein, to tell the truth, I'm not aware the extent to which reviewers of international journals are supposed to go.

S4/I-27/06/05

S4 also strengthens her case as reflected in Quote 3 in which she would be content when the articles are easy to read for their peer Indonesian colleagues within the confines of Indonesia.

Quote 3

R: Could you delineate your review of manuscripts in relation to international audience?

S4: Not that far of orienting the review for international readers. I assume it has more demanding criteria. Even though I wished to, I have not referred to those criteria. I'd rather be content when Indonesian peers find the articles easy to read.

Another editor (S1) shows a similar pessimism as she believes that orienting the journal toward international readership can only be carried out when the journal employs native speakers of English as editors in addition to the non-native English speaker editors. Quote 4 alludes to this issue.

Quote 4

R: $\quad$ So far [about international orientation]?

S1: No. Such an orientation requires the presence of a native speaker and we haven't had one. Otherwise, we cannot be so sure, for example, of what is meant by straightforward. We might think that native speakers of English tend to be straightforward; but, what is tricky is how straightforward is straightforward.

S1/III-04/04/05

Such a belief regarding the need for native speakers of English as editors exhibits a kind of paradox. S1 whose opinion is quoted above can actually be interpreted as the "cream" when she was selected as an undergraduate student and then a faculty member; this, in turn, warrants the validity of her appointment as an editor functioning as a discourse gatekeeper. She said that when she was interviewed for an undergraduate position, she felt that she "defeated" one of the interviewers and the interview was then taken over by the other interviewer (see Quote 5).

Quote 5

R: Would you mind telling me your academic life trajectories?

S1: $\quad$... the English Department (of the Institute for Teacher Training and Education) er:: had its er:: own entrance test I er:: I remember I was interviewed by the assistant of Mr. $\mathrm{N}$ and $\mathrm{Mr}$. $\mathrm{N}$ himself and er:: er:: instead of being asked I asked the assistant in English and er:: er:: he was kinda defeated (by me) and er:: er:: he didn't ask anything er:: it was taken by Mr. N. and er:: I was among a select few out of er:: some six hundred ...

\section{S1/III-04/04/05}

In short, the above quotes show a sort of paradoxical situation. On the one hand, the reviewers and/or editors are pessimistic; but, on the other hand, they seem to be cognizant of their function based on their ability as indicated by people's trust in their appointment as reviewers and/or editors. In what follows, we discuss such a kind of paradoxes or ambivalences further.

\section{Discussion}

It is interesting to note that, as the findings have demonstrated, the subjects of this research who were (and are) editors of two accredited Indonesian-based journals (TEFLIN Journal and Jurnal Ilmu Pendidikan (JIP)) were pessimistic about the quality of the articles they have been dealing with. Based on this judgment, they, in turn, felt 
justified not to orient the publication of the journals towards international readership (also see Basthomi, 2007).

The situation above poses some kinds of ambivalence, for TEFLIN Journal publishes articles written only in English and JIP publishes articles written either in English or Indonesian. It is understandable that when the articles are written in Indonesian, the main boundary of readership is very likely limited to Indonesia, despite the possibility that other readers outside of Indonesia might be interested to read. These include, for instance, academics in the area of Southeast Asian Studies and Comparative/International Educational Studies based in universities outside of Indonesia.

The foregoing points have identified some kinds of paradox experienced and/or enacted by the journal reviewer and/or editors. In this section, I make an attempt to provide some interpretive delineation of why the ambivalences are experienced and/or enacted by the editors. First of all, we need to acknowledge that academic culture in Indonesia is still nascent. Referring to Thomas (1973), Adnan (2004) reports that the first tertiary educational institution in Indonesia was established in 1920s. Even so, it was not oriented right from the very start to produce academics or researchers. It was set up to fulfill the demand for skilled personnel (needed and envisioned by the colonial Dutch government). Worse still, there were quite few indigenous Indonesians attending the institution. Even during the Japanese occupation in the 1940s, it was closed.

Later on, when it was re-operated, the Indonesian government was struggling over financial matters, which are not, I think, resolved much more elegantly today. Adnan (2004) further observes that postgraduate programs, which have the potential to be research-oriented, did not exist until 1980s. In other words, research activities which are crucial ingredients for publication have not been mature enough in the Indonesian academic life. Probably Moore (2011) also has the picture of the Indonesian academic situation in his mind when he stated that in some other countries in Southeast Asia, the research culture is just similar to that in Cambodia. So, probably, the pessimism voiced by the editors is rooted in this situation and thus warranted.

However, there is a pertinent question to raise as to why then the journals should also publish articles in English if they are not really intended for international audiences. Reminiscent of the issue raised by Adnan (2004) above, the publication of the articles in English may be deemed to function as training. Since both parties, the majority of the contributors or article authors and the reviewers and/or editors are Indonesian, they may feel that they do not have a real ownership of English; therefore, they feel they do not really have a feel of the language. This kind of feeling seems to be attributable to the shaping of the lack of confidence on the part of the editors.

The above point of ambivalence also leads to the next ambivalence which relegates to the notion of alienation in the sense of awareness of both the usefulness and futility of their endeavors in relation to the use of English as a foreign language in their native setting of Indonesia which, somehow, as they perceive it, will not parallel their counterparts in the other globe where English is used as the mother tongue. This is clearly reflected in the belief of S1 that the journal can orient to international readership only when the journal employs English native speakers as editors. In other words, this indicates the futility of the efforts made by Indonesian editors, yet, at the same time, she goes on to work which means she meets the expected functions as editor. This also means that she does something to ascertain the quality of the journal publication of some sorts.

The ambivalence also refers to the awareness that, despite the likely futility of their endeavors, they feel the prestige of being appointed gatekeepers of academic discourse. The appointment can be construed as a confirmation that they are socially believed to have the capability of assisting others with the publication of academic undertaking. My access to the editors' CV's affirms this point; the CV's mention their position as journal editors. In this regard, my belief is simple: if they deem their position as journal editors useless, they would refrain from the mention of the position in their CV's.

\section{Conclusions: Directions and Implications}

Reminiscent of qualitative research, particularly narrative research, this study has taken into the pool of the research subjects a small number of participants, that is, five reviewers and/or editors of two Indonesian-based accredited journals. Irrespective of the small number of the research subjects, the study has indicated some important issues pertinent to the voices of key individuals regarding the practice of journal publication in the Indonesian context vis-à-vis international academic discourse.

The study has demonstrated that the seemingly simple issue of editorship designation turns out to be not necessarily that simple. The ambivalences show the negotiated locus of the assessment of the roles and responsibilities the editors play and assume. This indexes how the editors see themselves in relations to their assessment of the writing ability of the journal article contributors and the nature of readership in Indonesia against the backdrop of the wider international academic discourse. Understanding this dynamics (Pennycook, 2001) may help instigate the cultivation 
of particular ideas for the betterment of Indonesian publication standing. Should this occur in us, a seed of transformation as produced through narrative research is warranted to expect (Johnson and Golombek, 2011; Nelson, 2011; Schnee, 2009).

Despite some highlights the study has thrown, it is not clear if the editors have some concerns regarding the non-English postcolonial position of Indonesia. Had this been brought to the attention of the editors during the interviews, we would have heard their voices around this issue so that a more complete interpretation of their negotiations of their meaning-making of their positions would have been clearer. Therefore, future narrative research projects need to take this issue into account.

It needs recapitulating that other than the lack of English competence as reflected in the article writing (as indicated in her view on the need to employ English native speakers as editors), the mediocre quality of the articles themselves is also the factor of their pessimism. However, it is not yet clear if the mediocre article quality has to do with the level of ease or hardship of access to relevant most up-to-date references. This point reminds me of an observation of a fellow from Chad, Africa. Completing his Ph.D. in an African university in a country other than his own and talking in the context of the U.S. he said, "My difficulty in completing my Ph.D. thesis is not so much about how to write but how to get access to what I need to read in order to write. Here in the U.S., I can access virtually all I want to read, but as I fly in back to my homeland, I will be simply totally cut from such an access."

Regarding the Indonesian context, probably Adnan (2004) is right in suggesting that Indonesian academics do not have much time to read references, for their time and energy tend to be allocated for moonlighting due to the underpay. However, to me, the fellow African's remark above rings louder in my mind. As academics become more experienced, they are supposed to develop some kinds of smart-critical reading ability. This can be construed that they would manage to do the critical-quick necessary reading of the materials for the purpose of writing pieces for publication (compare to Cheng's (2006) study on a graduate student's critical reading and writing). This raises a question as to whether Indonesian academics have the luxury of access to the needed materials similar to those enjoyed by their counterpart fellow academics in the better-off counties (cf. Belcher, 2007). This is exactly what has been voiced by a putative Indonesian academic, Masri Singarimbun (2003).

In the past five years in my profession, I have been responsible for handling a course on "Thesis Proposal Seminar" in which I have been applying results of my own reflective thinking regarding rhetorical consideration in writing a thesis proposal (Basthomi, 2006b). Much influenced by Swales (1990; 2004), I have been emphasizing the notion of "research space" in my course. However, as always, I have been confronted with a repeated question from my students concerning how they can get access to the needed reading materials so as to be able to tactically, critically, and eloquently carve out research spaces in their proposals (Belcher, 2009; Cheng, 2006; Swales, 1990; 2004). This is why my mind resonates well with the fellow African's comment abovementioned.

All this gives rise to the significance of open access publication which has just started to flourish recently. This can help defray the subscription costs that universities in developing counties cannot afford to pay. However, this is not the end of the story, for, subversive in nature, the open access journals vis-à-vis the elite subscription-based journals, need to prove their quality so as to be a real alternative in order to arrive at the balanced distribution of knowledge across the globe.

\section{Acknowledgement}

The writing of this article has been made possible with PAR 2011 under the auspices of Direktorat Pendidik dan Tenaga Kependidikan (Diktendik), Ditjen DIKTI, Kementerian Pendidikan dan Kebudayaan, Republik Indonesia. The author is therefore grateful to Diktendik for the support.

\section{References}

Adnan, Z. (2004). Citing Behaviours in Indonesian Humanities Research Articles. ASAA e- Journal of Asian Linguistics \& Language Teaching. Retrieved on October 2, 2005 from http://www.arts.unsw.edu.au/languages/asaa_ejournal

Basthomi, Y. (2006a). The rhetoric of research article introductions written in English by Indonesians. Unpublished Doctoral Dissertation. Malang: State University of Malang.

Basthomi, Y. (2006b). Rhetorical odyssey and trajectories: A personal reflection. TEFLIN Journal, 17(2), 99-110.

Basthomi, Y. (2007). Learning from the discursive practice of reviewing and editing: English research article publication in Indonesia. Jurnal Pendidikan dan Pembelajaran, 14(1), 65-74.

Becker, A. L. (1996). Beyond translation: Essays toward a modern philology. Ann Arbor: The University of Michigan Press. 
Belcher, D. D. (2007). Seeking acceptance in English-only research world. Journal of Second Language Writing, 16, 1-22. http://dx.doi.org/10.1016/j.jslw.2006.12.001

Belcher, D. D. (2009). How research space is created in a diverse research world. Journal of Second Language Writing, 18, 221-234. http://dx.doi.org/10.1016/j.jslw.2009.08.001

Bell, J. S. (2011). Reporting and publishing narrative inquiry in TESOL: Challenges and rewards. TESOL Quarterly (Reports and Reflections), 575-584. http://dx.doi.org/10.5054/tq.2011.256792

Blanton, L. L. (2005). Student, interrupted: A tale of two would-be writers. Journal of Second Language Writing, 14, 105-121. http://dx.doi.org/10.1016/j.jslw.2005.04.001

Cheng, A. (2006). Analyzing and enacting academic criticism: the case of an L2 graduate learner of academic writing. Journal of Second Language Writing, 15, 279-306. http://dx.doi.org/10.1016/j.jslw.2006.09.002

Cadman, K., \& Brown, J. (2011). TESOL and TESD in remote aboriginal Australia: The "true" story? TESOL Quarterly, 45(3), 440-462. http://dx.doi.org/10.5054/tq.2011.256794

Flowerdew, J. (2001). Attitudes of journal editors to nonnative speaker contributions. TESOL Quarterly, 35(1), 121-150.

Fraenkel, J. R., \& Wallen, N. E. (2003). How to design and evaluate research in education (5 $5^{\text {th }}$ ed.). New York: MacGraw-Hill.

Gordon, C. (2009). Making meanings, creating family: Intertextuality and framing in family interaction. Oxford: Oxford University Press.

Hayes, D. (2010). Duty and Service: Life and career of a Tamil teacher of English in Sri Lanka. TESOL Quarterly, 44(1), 58- 83. http://dx.doi.org/10.5054/tq.2010.214048

Johnson, K. E., \& Golombek, P. R. (2011). The transformative power of narrative in second language teacher education. TESOL Quarterly, 45(3), 486-509. http://dx.doi.org/10.5054/tq.2011.256797

Kang, J. Y. (2006). Producing culturally appropriate narratives in English as a foreign language: A discourse analysis of Korean EFL learners' written narratives. Narrative Inquiry, 16(2), 379-407.

Mirahayuni, N. K. (2002). Investigating textual structure in native and non-native English research articles: Strategy differences between English and Indonesian writers. Unpublished Ph.D. Thesis. Sydney: The University of New South Wales.

Montminy, M. (2010). Context and communication: A defense of intentionalism. Journal of Pragmatics, 42, 2910-2918. http://dx.doi.org/10.1016/j.pragma.2010.06.010

Moore, S. (2011). The struggle to develop a "research culture" in a developing country. TESOL Quarterly, 45(2), 334-343. http://dx.doi.org/10.5054/tq.2011.254525

Nelson, C. D. (2011). Narratives of classroom life: Changing conceptions of knowledge. TESOL Quarterly, 45(3), 463-485. http://dx.doi.org/10.5054/tq.2011.256799

Pennycook, A. (2001). Critical applied linguistics: A critical introduction. Mahwah, New Jersey and London: Lawrence Erlbaum Associates, Publishers.

Safnil. (2000). Rhetorical structure analysis of the Indonesian research articles. Unpublished Ph.D. Thesis. Canberra: Australian National University.

Schnee, E. (2009). Writing the personal as research. Narrative Inquiry, 19(1), 35-51. http://dx.doi.org/10.1075/ni.19.1.03sch

Seidman, I. E. (1991). Interviewing as qualitative research: A guide for researchers in education and the social sciences. New York and London: Teachers College, Columbia University.

Singarimbun, M. (2003). Reflections from Yogya: Portraits of Indonesian social life (trns.). Yogyakarta: Galang Press.

Sipe, L. R. (2008). Storytime: Young children's literary understanding in the classroom. New York and London: Teachers College, Columbia University.

Swales, J. M. (1990). Genre analysis: English in academic and research settings. Cambridge: Cambridge University Press.

Swales, J. M. (2004). Research genres: Explorations and applications. Cambridge: Cambridge University Press. 
Tsui, A. B. M. (2007). Complexities of identity formation: A narrative inquiry of an EFL teacher. TESOL Quarterly, 41(4), 657-680.

Vásquez, C. (2011). TESOL, teacher identity, and the need for "small story" research. TESOL Quarterly, 45(3), 535-545. http://dx.doi.org/10.5054/tq.2011.256800

Xu, S., \& Connelly, M. (2010). Narrative inquiry for school-based research. Narrative Inquiry 20(2), 349-370. http://dx.doi.org/10.1075/ni.20.2.06xu

\section{Author}

Yazid Basthomi is Lektor at the English Department, Faculty of Letters, Universitas Negeri Malang (State University of Malang), Indonesia. His recent publications include 'Competing discourses in thesis advisement: Reflecting on the writing of terms of address in acknowledgements section.' Selected Articles in English Language Teaching. Jakarta: IIEF \& RELO-US. Embassy (2010). 